\title{
Trans-Esterification Optimization Process for Biodiesel Production from Palm Kernel Oil using Response Surface Methodology
}

\author{
",1RABIU, T.O., ${ }^{2}$ FOLAMI, N.A., ${ }^{1}$ BADIRU, N.A., \\ ${ }^{2}$ KINGHSLEY, N.A., ${ }^{3}$ DARE, B.T., ${ }^{1}$ ADIGUN, I.A.
}

${ }^{1}$ Department of Mechanical Engineering, Lagos State Polytechnic, Ikorodu Lagos, Nigeria

${ }^{2}$ Department of Chemical Engineering, Lagos State Polytechnic, Ikorodu, Lagos, Nigeria

${ }^{3}$ Department of Agriculture and Bio-Environmental Engineering, Lagos State Polytechnic, Ikorodu, Lagos

*trabiun@yahoo.com

Received: $26^{\text {th }}$ April 2021

Accepted: $13^{\text {th }}$ May 2021

Published: $5^{\text {th }}$ August 2021

https://doi.org/10.47545/etrj.2021.6.2.079

\begin{abstract}
The ever-growing concern for the safety of lives and the environment as well as the depletion in fossil fuels reserves across the globe has led to the keen interests of many researchers in the field of renewable energy. This study was therefore undertaken to investigate the trans-esterification optimization process for biodiesel production from palm kernel using response surface methodology. The materials for the trans-esterification processes were palm kernel oil, Methanol and sodium hydroxide. The effects of reaction temperature $\left({ }^{\circ} \mathrm{C}\right)$, catalyst concentration $(\mathrm{wt} \%)$ and reaction time $(\mathrm{min})$ on the yield were evaluated. The properties of the biodiesel produced showed that it met the ASTM standard for biodiesel. A quadratic polynomial model, Yield $(\%)=78.60-3.12 \mathrm{~A}-.62 \mathrm{~B}+0.00 \mathrm{C}$ $-0.75 \mathrm{AB}-3.50 \mathrm{AC}+1.50 \mathrm{BC}+2.82 \mathrm{~A}^{2}-0.18 \mathrm{~B}^{2}+1.08 \mathrm{C}^{2}$, was developed that can be used to predict yield of biodiesel at any value of the different parameters investigated. The ANOVA for the model of the biodiesel yield obtained indicates that the models fit well in describing the relationship between the predictor (biodiesel yield) and the factors (methanol to oil ratio, catalyst concentration and reaction time). The optimal trans-esterification conditions were found to be $60^{\circ} \mathrm{C}$ for temperature, 60 minutes for reaction time, $0.878 \mathrm{w} \%$ of oil as Sodium hydroxide (catalyst) concentration and methanol/oil ratio of 1:6. At these optimal conditions, the biodiesel yield was fond to be $89.32 \%$ The generated biodiesel had high cetane number, better engine ignitability and poses lesser pollution problems than petroleum diesel.
\end{abstract}

Keywords: Biodiesel, Optimization, Palm kennel oil, RSM, Transesterification.

\section{INTRODUCTION}

The high energy demand, pollution, as well as global consensus that fossil energy sources are finite, making it increasingly necessary to develop a renewable energy source of limitless duration, smaller environmental impacts, technically feasible and readily available $[14,19]$. Biodiesel have been reported as a promising long term renewable energy source [24]. Biodiesel, an environmentally friendly fuel, has many merits. It is derived from renewable domestic resource; it is biodegradable and non-toxic [29]. Biodiesel is pursued not only for the consideration of the future shortage of petroleum supplies but also for the well-being of the environment [30]. Diesel fuels have an essential function in the industrial economy of a developing country. Various plant oils have been converted into biodiesel and they work well in biodiesel engines [20] One possible alternative to fossil fuel is the use of oil of plant origin like vegetable oil, Palm kernel oil, and so on [26].

Available statistical data ranked Nigeria as one of the ten largest oil producers in the world with a whooping 36,220 million barrels of proven oil reserves, 184,160 trillion cubic feet of natural gas reserves at the beginning of year 2018 and at the end of the year 2018 respectively [25]. The amazing oil wealth notwithstanding, the Energy Commission of Nigeria (ECN) expressed fears over future depletion of these fossil fuels and its severe environmental impacts [6]. Petroleum based energy sources pose severe threats to the environment from hazardous emissions. Huge level of fossil fuel combustion has resulted in the concentration of carbon (IV) oxide which causes dramatic global climate change, air pollution, acid rain and other devastating effects [16].

Trans-esterification of triacylglycerols (triglycerides) is a process that converts vegetable oils into fuel for diesel engine [31]. Oils and fats are essentially esters of glycerol and fatty acids, derived from plant and animal sources. $\begin{array}{lll}\text { Rabiu et al, } 2021 & 7 & \text { www.etri.com.ng }\end{array}$ (C) 2021 Faculty of Engineering, Lagos State University, Ojo. Nigeria. 
Different oils have different acid compositions and hence different viscosities. Oils are normally liquid at ambient temperature, fats are normally solid [17,27]. Vegetable oil is an important renewable feedstock in the long term (2016 - 2025) vision of providing secure, abundant, cost effective and clean source of energy for Nigeria [5]. Common vegetable oils in Nigeria include palm oil, palm kernel oil, groundnut oil, peanut oil, cotton seed oil and soybean oil [12]. Animal fat such as tallow, lard, chicken fats are useful in biodiesel production. Catalysts are necessary to reduce the time and energy requirement for the trans-esterification reaction. The catalyst lowers the activation energy of the reaction by providing an alternative path that avoids the slow, rate determining step of the uncatalyzed reaction $[2,4]$.

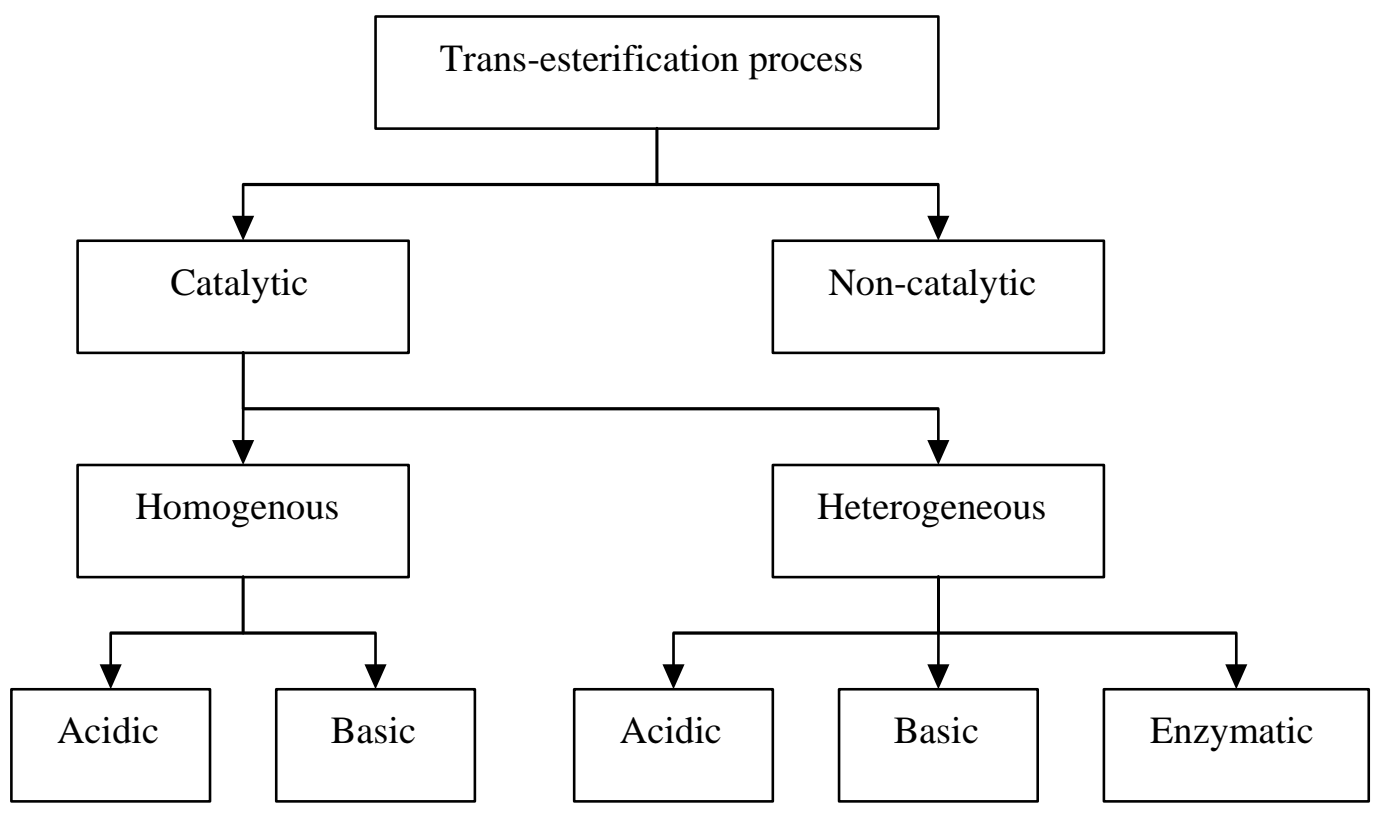

Figure 1. Division of methods in the trans-esterification process. [15]

Moisture and free fatty acids are two key parameters in determining the viability of the feedstock (vegetable oils) in the trans-esterification process. Generally, moisture and free fatty acids content of the feedstock must be reduced or lowered ( $<0.5 \%$ for homogenous process) to avoid its undesirable effect on the catalyst and the transesterification reaction [14]. Based on the stoichiometry of trans-esterification reaction, every mole of triglyceride requires three moles of alcohol to produce three moles of fatty acid alkyl esters and one mole of glycerol [23]. In the trans-esterification process however, alcohol is supplied in excess to induce higher yield of fatty acid alkyl esters. Molar ratio of oil to alcohol at 1:6 is considered as the standard ratio [13]. However, other researches also shown that molar ratio of oil to alcohol from 1:5 [6] up to 1:8 [21], 1:9 [22], 1:12 [19], and higher could also be used.

The type and amount of catalyst required in the trans-esterification process usually depend on the quality of the feedstock and method applied for the trans-esterification process. For a purified feedstock, any type of catalyst could be used for the trans-esterification process. However, for feedstock with high moisture and free fatty acids contents, homogenous trans-esterification process is unsuitable due to high possibility of saponification process instead of trans-esterification process to occur $[9,13]$. Results of researches have shown that the reaction time for a non-catalytic trans-esterification process using supercritical alcohol is shorter compared to conventional catalytic trans-esterification process [9]. For a heterogeneous trans-esterification process, the reaction period varies depending on the reactivity and type of the solid catalyst used. For a practical and economic feasible transesterification process, it is necessary to limit the reaction time at a certain period. Longer reaction time could also permit reversible trans-esterification reaction to occur, which eventually could reduce the yield of fatty acid alkyl esters. Thus, optimization of reaction time is also necessary [23]. The operating temperature for transesterification process depends on the method used. Certain processes, such as homogenous trans-esterification process and enzymatic trans-esterification process, generally require moderate temperature to commence the trans-esterification reaction. However, non-catalytic trans-esterification process requires high temperature and pressure to yield the desired product [18]. 


\section{MATERIALS AND METHODS}

\subsection{Materials}

Palm Kernel oil, methanol, sulphuric acid, sodium hydroxide pellets, isopropyl alcohol, potassium hydroxide pellets, phenolphthalein, sodium thiosulphate, Wij's reagent, chloroform, starch, potassium iodide, ethanol, diethyl ether and hydrochloric acid. Glass wares used were $1000 \mathrm{ml}$ conical flask, $1000 \mathrm{ml}$ beaker, $500 \mathrm{ml}$ beaker, separating funnel, $500 \mathrm{ml}$ glass bottles condenser, $500 \mathrm{ml}$ round bottom flask, $100 \mathrm{ml}$ conical flasks and density bottle, hot plate, magnetic stirrer, thermometer, hammer mill, Ball mill and muffle furnace.

\subsection{Experimental Procedure}

Palm Kernel oil was purchased at a local market around Abule-Egba in Lagos State, Nigeria. Prior to use in the trans-esterification process, the palm kernel oil was filtered with the use of a white cloth as sieve to remove any entrained solid that may be suspended in the oil. The palm kennel oil was esterified to reduce FFA to about $1.40 \%$. This was done by measuring methanol of volume of about $20 \%$ the weight of the oil and $\mathrm{H}_{2} \mathrm{SO}_{4}=0.05 * \mathrm{FFA}$ of the oil. The methanol and $\mathrm{H}_{2} \mathrm{SO}_{4}$ are then mixed together. This mixture was slowly added to the oil while the mixing continued for one hour at a temperature of $60^{\circ} \mathrm{C}$.

$50 \mathrm{~g}$ of the preheated palm kernel oil (about $60^{\circ} \mathrm{C}$ ) was mixed with a mixture of methanol and sodium hydroxide catalyst and stirred on a hot plate with magnetic stirrer at a speed of 150rpm. while maintaining the temperature at $60^{\circ} \mathrm{C}$. The reaction was allowed to proceed for the specified length of time. After the time specified, the products obtained were transferred to separating funnel and allowed to stand for $24 \mathrm{~h}$. The products separated into two distinct layers, a light-yellow top layer (biodiesel) and a reddish-brown bottom layer (glycerol). Biodiesel generated was cleansed of impurities, such as unconverted methanol, catalyst, soap and traces of glycerol by washing with several charges of hot distilled water and dried afterward at $120^{\circ} \mathrm{C}$ in an oven for $30 \mathrm{~min}$ to eliminate residual moisture

\section{RESULTS AND DISCUSSION}

The FFA content of the crude palm kernel oil was found to be high (9.63\%) therefore, the oil was esterified twice to lower the FFA to a value of $1.40 \%$ before proceeding to trans-esterification. This was to ensure that the catalyst $(\mathrm{NaOH})$ does not react with FFA to produce soap and water which would lead to low yield of the biodiesel.

\subsection{Biodiesel Yield}

Response surface methodology (RSM) provides a superb statistical tool for design and analysis of experiments aimed at process optimization. This tool was used to optimize the biodiesel yield from palm kernel oil using the three variables of Methanol to oil ratio, catalyst concentration and reaction time as depicted in Table 1. The reaction was carried out at a constant temperature of $60^{\circ} \mathrm{C}$.

Saponification values of propyl esters prepared from palm kernel oil was less than those prepared from crude oils. This could be due to the presence of phosphatides which were removed during degumming and refining process. The saponification values of propyl esters were $245 \mathrm{mg} \mathrm{KOH} / \mathrm{g}$. The average molecular weight of oil can be calculated by multiplying the inverse of saponification value by $168000[1,24]$. Therefore, the higher the saponification value, the lower the molecular weight. The iodine value of the conventional diesel fuel was approximately 10 [14]. Therefore, the biodiesel had significantly higher degree of unsaturation than diesel fuel (64.9g of iodine/g for palm kernel biodiesel), though the iodine values of the refined and unrefined oils did not show any appreciable difference. This implies that diesel engine utilizing biodiesel is more susceptible to gum formation than that utilizing conventional diesel fuel due to the higher iodine values of biodiesel. The acid value of propyl esters prepared from palm kernel oil was $0.3 \mathrm{mgkOH} / \mathrm{g}$ and $19.28 \mathrm{mgKOH} / \mathrm{g}$ for unrefined oil and 1.74 $\mathrm{mgKOH} / \mathrm{g}$ for refined oils. The results shows that both refined and unrefined oils could not be used directly as fuel in diesel engine since their acid value is above the ASTM requirement while the results of biodiesel produced from this oil conform to ASTM D 6751 standards [7]. Within the limit specified for biodiesel fuel in Europe (EN 14214: $086-0.90$ ). Specific gravity (also known as relative density) refers to the ratio of the density of a fuel to the density of water at the same temperature. The level of agreement recorded in specific gravities for the PKO biodiesels is an important pointer to suitability of the biodiesel fuel substitute as important fuel performance indicators such as heating values, fuel storage is correlated with specific gravity $[1,29]$. Fuel viscosity is regulated by the standards at $40^{\circ} \mathrm{C}$. From Table 2, PKO biodiesel has higher viscosity than conventional diesel fuel but falls within that of ASTM Biodiesel which is in agreement with reports from several researchers $[1,11]$.

The specific gravity obtained for PKO biodiesel (0.89) was slightly higher than the values for ASTM Biodiesel $(0.88)$ and standard petro-diesel (0.84-0.86). 
Table 1. Design of Experiment of Three Variables with the Responses

\begin{tabular}{|c|c|c|c|c|c|}
\hline \multirow[b]{2}{*}{ Std } & \multirow[b]{2}{*}{ Run } & Factor 1 & Factor 2 & Factor 3 & Response 1 \\
\hline & & $\begin{array}{l}\text { A: methanol/oil } \\
\text { ratio }\end{array}$ & $\begin{array}{c}\text { B: catalyst conc. } \\
\text { (\% weight oil) }\end{array}$ & $\begin{array}{l}\text { C: reaction } \\
\text { time (mins) }\end{array}$ & Yield (\%) \\
\hline 7 & 1 & 6 & 1 & 60 & 90 \\
\hline 16 & 2 & 7.5 & 1 & 45 & 82 \\
\hline 11 & 3 & 7.5 & 0.8 & 60 & 80 \\
\hline 5 & 4 & 6 & 1 & 30 & 82 \\
\hline 4 & 5 & 9 & 1.2 & 45 & 75 \\
\hline 3 & 6 & 6 & 1.2 & 45 & 82 \\
\hline 15 & 7 & 7.5 & 1 & 45 & 78 \\
\hline 1 & 8 & 6 & 0.8 & 45 & 86 \\
\hline 2 & 9 & 9 & 0.8 & 45 & 82 \\
\hline 8 & 10 & 9 & 1 & 60 & 76 \\
\hline 17 & 11 & 7.5 & 1 & 45 & 76 \\
\hline 10 & 12 & 7.5 & 1.2 & 30 & 76 \\
\hline 12 & 13 & 7.5 & 1.2 & 60 & 78 \\
\hline 13 & 14 & 7.5 & 1 & 45 & 79 \\
\hline 14 & 15 & 7.5 & 1 & 45 & 78 \\
\hline 6 & 16 & 9 & 1 & 30 & 82 \\
\hline 9 & 17 & 7.5 & 0.8 & 30 & 84 \\
\hline
\end{tabular}

Table 2. Properties of the Biodiesel Compared to Petroleum Diesel and ASTM standard

\begin{tabular}{|c|c|c|c|c|}
\hline Properties & PKO & $\begin{array}{l}\text { Biodiesel } \\
\text { Produced }\end{array}$ & $\begin{array}{c}\text { ASTM } \\
\text { Standard }\end{array}$ & $\begin{array}{c}\text { Petroleum } \\
\text { diesel }\end{array}$ \\
\hline Specific gravity & 0.94 & 0.89 & 0.88 & $\begin{array}{c}0.84- \\
0.86\end{array}$ \\
\hline Viscosity $\left(\mathrm{mm}^{2} / \mathrm{s}\right)$ & 35.1 & 4.95 & $1.9-6.0$ & $\begin{array}{l}2.04- \\
3.23\end{array}$ \\
\hline Flash point $\left({ }^{\circ} \mathrm{C}\right)$ & - & 179 & $130 \mathrm{~min}$ & $68-94$ \\
\hline Pour point $\left({ }^{\circ} \mathrm{C}\right)$ & - & -1 & - & $-` 15$ \\
\hline Cloud point $\left({ }^{\circ} \mathrm{C}\right)$ & - & 2.5 & $15-(-3)$ & -12 \\
\hline $\begin{array}{l}\text { Saponification value } \\
\text { (mgKOH/g oil) }\end{array}$ & 245 & 172.4 & - & - \\
\hline $\begin{array}{l}\text { Iodine value ( } \mathrm{g} \mathrm{I}_{2} / 100 \mathrm{~g} \\
\text { oil) }\end{array}$ & 64.9 & 64.5 & - & - \\
\hline Acid value (mgKOH/g oil) & 19.26 & 0.3 & $0.8 \max$ & - \\
\hline Water Content (\%) & - & 0.006 & $0.5 \max$ & - \\
\hline Calorific Value (MJ/kg) & - & 36.95 & $34-45$ & $78-99$ \\
\hline $\begin{array}{l}\text { Carbon Residue on } 10 \% \\
\text { evaporation (wt. \%) }\end{array}$ & - & 0.045 & 0.042 & 0.095 \\
\hline Cetane number & - & 63.45 & $47-65$ & $41-48$ \\
\hline Ash Content & - & 0.0024 & 0.0001-0.0005 & $0.01-0.1$ \\
\hline
\end{tabular}


The Pour Point (PP) and Cloud Point (CP) of PKO biodiesel in this present work were found to be -1 and $2.5^{\circ} \mathrm{C}$, respectively (Table 3.2). According to ASTM D 6751 standard for biodiesel, and standard petro-diesel, no limit is specified for PP and CP. Probably, the reason is that the climate conditions in the world vary considerably, thus affecting the needs of biodiesel users in specific regions. The implication of high cloud and pour points is that they will result in fuel line clogging. Flash point (FP) is the temperature at which fuel will ignite when exposed to a flame or spark. The biodiesel synthesized from PKO had a FP of $179^{\circ} \mathrm{C}$ and it is within the ASTM D 6751 standard specifications. The FP obtained is higher than that of fossil diesel $\left(63-94{ }^{\circ} \mathrm{C}\right)$ and that of PKO biodiesel $\left(156{ }^{\circ} \mathrm{C}\right)$ cited by Phan and Phan (2013). A higher value of FP is often associated with a reduced risk of fire. This property serves as an advantage of biodiesel over fossil diesel [3]. The water content determined for PKO biodiesel was $0.03 \%$ which is in accordance with ASTM D6751 standards (Table 2). The implication is that the quality of biodiesel is not affected since the moisture content in the WFO biodiesel is in line with the standard. High water content may cause poor combustion, plugging and smoking.

Ash content of fuel is the non- combustible residue left after fuel is burnt. The ash content estimated for PKO Biodiesel was $0.0042 \mathrm{wt} . \%$. Heating value is the energy released after the complete combustion reaction of fuel at a constant pressure or volume. It was determined in accordance with the ASTM D240. The higher the heating value of the fuel, the lower the fuel consumption needed to obtain the same output of engine power. The PKO biodiesel is lower than that of fossil diesel because of extra oxygen carbon [1,6]. Carbon residue is an important indicator to assess the tendency of fuel to form carbonaceous deposits in engine which cause a blockage in the nozzles and cracking of components. The carbon residue obtained for PKO biodiesel was 0.053 wt.\%. As could be seen in Table 2, the carbon residue of the PKO ASTM standard Biodiesel is $0.042 \mathrm{wt}$. \% less than that of petrodiesel (0.095 wt.\%). PKO biodiesel produced in this study is better than that of the conventional diesel since the biodiesel cannot cause operational problems such as blockage of nozzles and cracking of components $[1,29]$.

Effect of Methanol to Oil Ratio and Catalyst Concentration on Yield: As observed from Figure 2, the yield gradually reduces as the methanol oil ratio increased from 6 to 9 while also, the catalyst concentration increased the yield from $0.8 \%$ weight of oil till it got to $1 \%$ and then dropped the yield as it approached the $1.2 \%$ value. This showed that the highest yield was got at methanol to oil ratio of 6 and catalyst concentration of $1 \%$ weight of oil. This is similar to what was reported in the work done by Dube and Mishra, (2016) [10] and Ayoola, et.al., (2016) [8]. In addition, literatures reveal that the low yield of biodiesel at excess methanol per oil of greater than optimum value during trans-esterification increases the polarity of the reaction mixture, thus increasing the solubility of glycerol and this promotes the reversible reaction between glycerol and biodiesel, thereby reducing biodiesel yields [8].

Effect of Reaction Methanol to Oil Ratio and Reaction Time on Yield: Figure 3 shows the interaction between methanol to oil ratio, reaction time and the effect on yield. It is also observed that the highest yield occurred at molar ratio of 6 and reaction time of 60 mins. Although, high yield was also observed at molar ratio of 9 and 30 mins, the highest was at ratio 6 and 60 mins. Earlier reports also showed that providing sufficient time during trans-esterification reaction drive the reaction forward into completion for biodiesel production [28].

Effect of Reaction Catalyst Concentration and Reaction Time on Yield: From Figure 4 catalyst concentration can be observed to give high yield at $1.0 \%$ weight of oil and 60 mins reaction time which also is in line with previous works from literature $[6,8,28]$. As reported earlier, catalyst concentration of $1.0 \%$ weight of oil is regarded as optimum level. Beyond this concentration, decrease in biodiesel yields (due to saponification reaction) sets in, resulting mainly from the reaction between the excess catalyst to form soap, which inhibits biodiesel yield [28]. The interactive effect of catalyst concentration and the reaction time reveals that the reaction time should be kept at 60 min to promote the forward reaction and thus ensure favourable biodiesel yield [8].

Biodiesel Yield Model: The response (biodiesel yield) model, as function of the three parameters is a quadratic equation as stated in Equation below:

Yield $(\%)=78.60-3.12 \mathrm{~A}-2.62 \mathrm{~B}+0.00 \mathrm{C}-0.75 \mathrm{AB}-3.50 \mathrm{AC}+1.50 \mathrm{BC}+2.82 \mathrm{~A}^{2}-0.18 \mathrm{~B}^{2}+1.08 \mathrm{C}^{2}$

Where $\mathrm{A}=$ methanol to oil ratio, $\mathrm{B}=$ Catalyst concentration and $\mathrm{C}=$ reaction time

With R-Square $=91.23 \%$, R-Square $(\operatorname{adj})=.79.95 \%$ and R-Square $($ pred. $)=67.95 \%$

Analysis of Variation (ANOVA) using $\boldsymbol{P}$ and $\boldsymbol{F}$-Values: The ANOVA for the model of the biodiesel yield obtained indicates that the models fit well in describing the relationship between the predictor (biodiesel yield) and the factors (methanol to oil ratio, catalyst concentration and reaction time). This is as a result of the calculated high f-values and low p-values. The low p-values (0.0058) justifies the significance of each term of the model 
because p-values less than 0.0500 indicate model terms are significant. Values greater than 0.1000 indicate the model terms are insignificant. Also, the high values of $\mathrm{R}^{2}$ and $\mathrm{R}^{2}$ (adjusted) shows the suitability of the models by describing the extent to which responses are reflected. The closer the value of the $\mathrm{R}^{2}$ is to $100 \%$ the better the model. Finally, the difference between the predicted $\mathrm{R}^{2}$ and the adjusted $\mathrm{R}^{2}$ is less than 0.2 which indicates that the model can be used successfully and accurately.

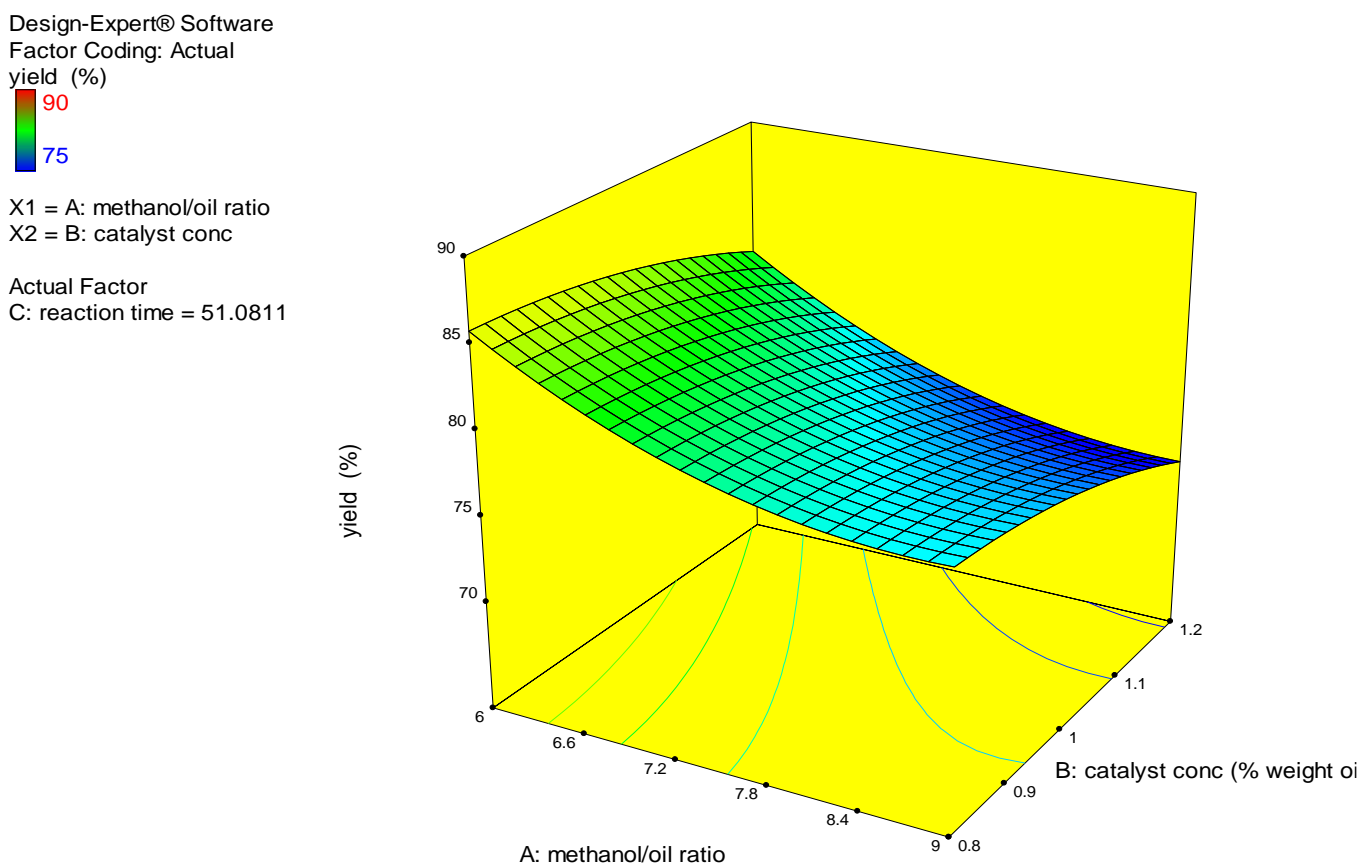

Figure 2: Response Surface Diagram for the Methanol/Ratio and Catalyst against the Yield

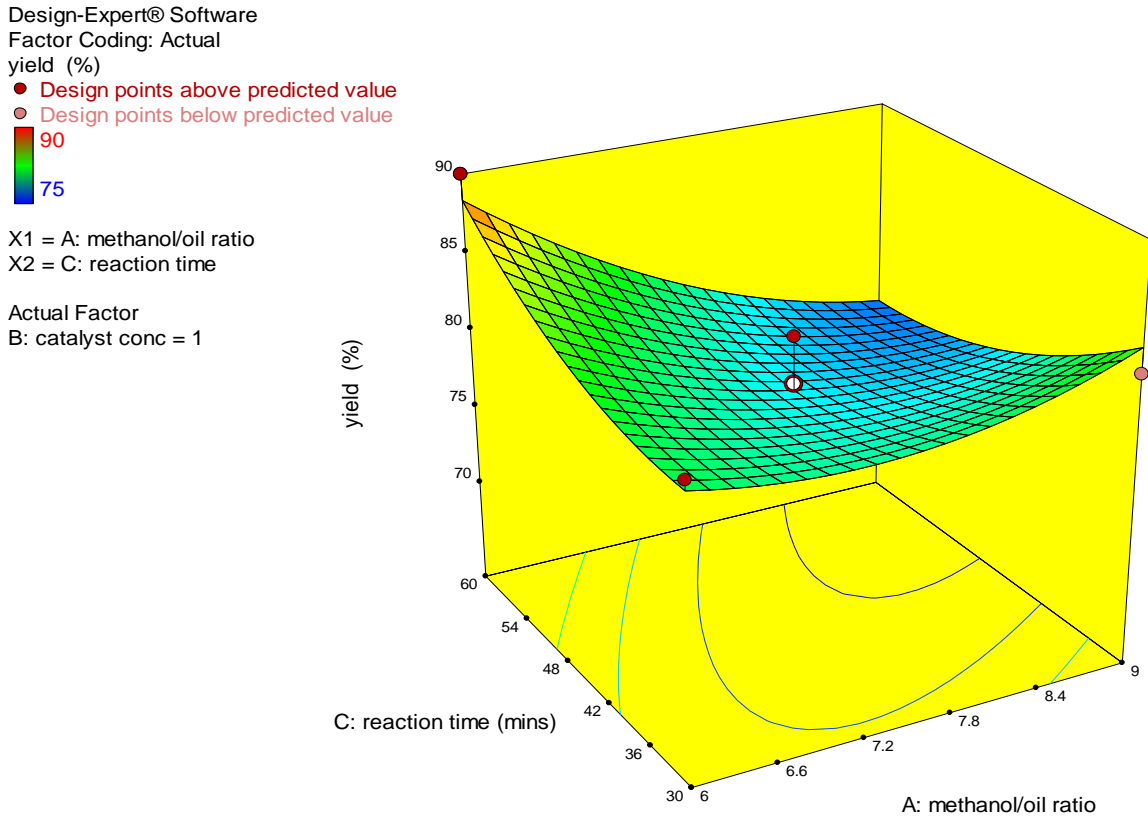

Figure 3: Response Surface Diagram for Reaction Time and Methanol/Ratio against the Yield 


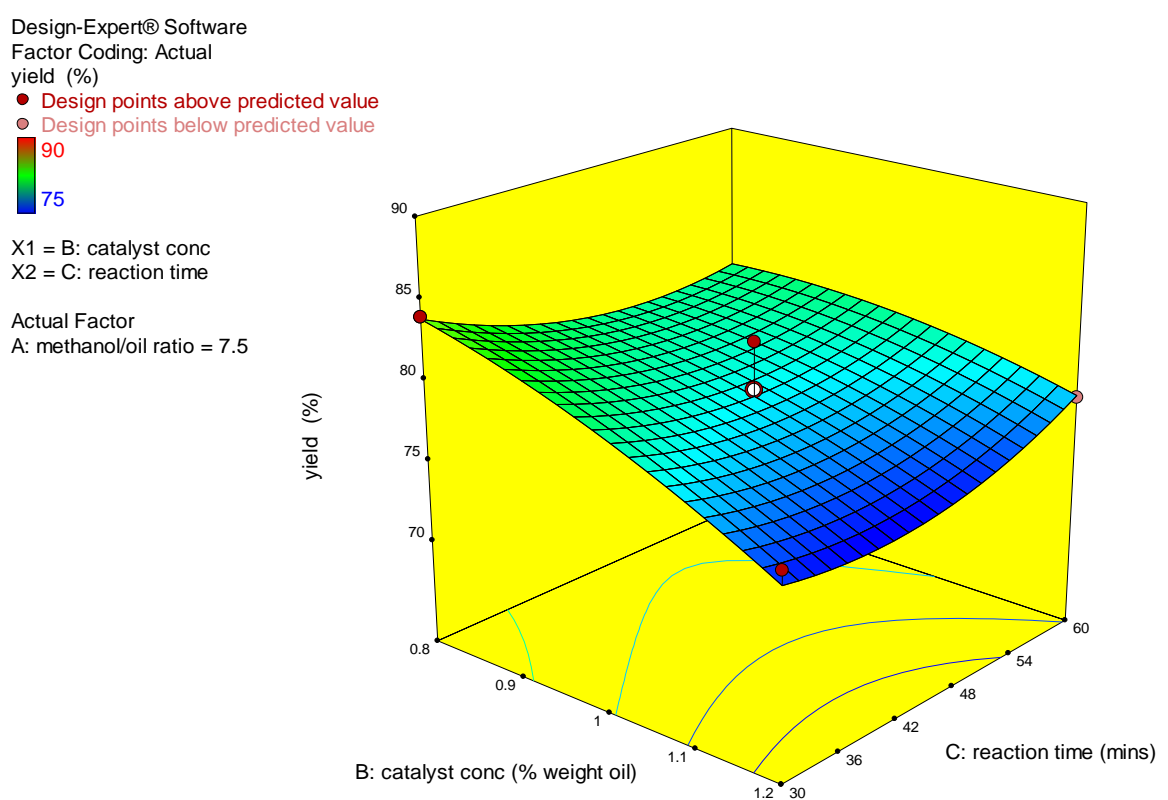

Figure 4: Response Surface Diagram for Catalyst and Reaction Time against the Yield

Table 3. Analysis of Variance Table

\begin{tabular}{ccccccc}
\hline Factor & $\begin{array}{c}\text { Sum of } \\
\text { Squares }\end{array}$ & $\begin{array}{c}\text { Degree } \\
\text { of } \\
\text { freedom }\end{array}$ & $\begin{array}{c}\text { Mean } \\
\text { Square }\end{array}$ & $\begin{array}{c}\text { F } \\
\text { Value }\end{array}$ & $\begin{array}{c}\text { p-value } \\
\text { Prob }>\end{array}$ & \\
\hline F & \\
\hline $\begin{array}{c}\text { Model } \\
\text { A-methanol/oil } \\
\text { ratio }\end{array}$ & 233.43 & 9 & 25.94 & 8.09 & 0.0058 & significant \\
B-catalyst conc. & 58.12 & 1 & 78.12 & 24.36 & 0.0017 & \\
C-reaction time & 0 & 1 & 55.12 & 17.19 & 0.0043 & \\
AB & 2.25 & 1 & 2.25 & 0.7 & 0.4299 & \\
AC & 49 & 1 & 49 & 15.28 & 0.0058 & \\
BC & 9 & 1 & 9 & 2.81 & 0.1378 & \\
$\mathrm{~A}^{2}$ & 33.6 & 1 & 33.6 & 10.48 & 0.0143 & \\
$\mathrm{~B}^{2}$ & 0.13 & 1 & 0.13 & 0.04 & 0.8468 & \\
$\mathrm{C}^{2}$ & 4.87 & 1 & 4.87 & 1.52 & 0.2578 & \\
Residual & 22.45 & 7 & 3.21 & & & not \\
Lack of fit & 3.25 & 3 & 1.08 & 0.23 & 0.8743 & significant \\
Pure error & 19.2 & 4 & 4.8 & & & \\
Cor total & 255.88 & 16 & & & & \\
\hline
\end{tabular}

The Model F-value of 8.09 implies the model is significant. There is only a $0.58 \%$ chance that an F-value this large could occur due to noise.

\section{CONCLUSION}

Relying on fossil fuel alone is no longer realistic due to global depletion of the non-renewable energy sources and its attendant negative environmental impact. This emphasizes the relevance of this work which was undertaken to investigate the optimization of trans-esterification of palm kernel oil to produce biodiesel using response surface methodology. In the trans-esterification processes, the main materials used were palm kernel oil, Methanol and 
sodium hydroxide. The effects of reaction temperature $\left({ }^{\circ} \mathrm{C}\right)$, catalyst concentration $(\mathrm{wt} \%)$ and reaction time (min) on the yield were evaluated. The properties of the biodiesel produced showed that it met the ASTM standard for biodiesel. A quadratic polynomial model was developed that can be used to predict yield of biodiesel at any value of the different parameters investigated. The optimal trans-esterification conditions were found to be $60{ }^{\circ} \mathrm{C}$ for temperature, 60 minutes for reaction time, $0.878 \mathrm{w} \%$ of oil as Sodium hydroxide (catalyst) concentration and methanol/oil ratio of 1:6. At these optimal conditions, the biodiesel yield was fond to be $89.32 \%$ The generated biodiesel had high cetane number, better engine ignitability and poses lesser pollution problems than petroleum diesel.

\section{REFERENCES}

[1] Ajav. E. H. and Akingbehin A. R., (2012). "Optimization of experimental conditions for biodiesel production from alkali-catalysed trans-esterification of Jatropha curcus oil”. Energy for Sustainable Development. Vol. IX, No. 3. pp. 13-18.

[2] Akhabue, C. E. and Okwundu S. O. (2017). "Monitoring the trans-esterification reaction of castor oil and methanol by ultraviolet visible spectroscopy". Biofuels. Available in http://doi.org/10.1080/ 17597269.2017.1338128.

[3] Akoh, M. O., Martins, E.J, Rashid M. T. and Jekayinfa S.O. (2014). "Biodiesel production from Nigerian palm kernel oil: effect of KOH concentration on yield. Energy for Sustainable Development. XI (3):77-82.

[4] Alacantara, R., J. Amores, L. Canoira, E. Fidalgo, M.J. Franco and A. Navarro. (2010). "Catalytic production of biodiesel from soybean oil, used frying oil and tallow”. Biomass and Bioenergy, pp. 515527

[5] Alamu, O.J., Waheed, M.A. and Jekayinfa, S.O. (2007). Alkali-catalyzed laboratory production and testing of biodiesel fuel from Nigerian palm kernel oil”. Agricultural Engineering International: the CIGR Ejournal. Manuscript Number EE 07 009. Vol. IX.

[6] Alamu, O.J., Waheed, M.A. and Jekayinfa, S.O. (2015). Effect of ethanol-Palm kernel oil ratio on alkalicatalysed biodiesel yield. Fuel. JFUE-D-07-00416. In print.

[7] ASTM. (1995). ASTM Book of Standard Test Methods; America Society for Testing Materials: Philadelphia, PA, pp 1-8, 268-271.

[8] Ayoola, A.A., F.K. Hymore, M.A. Obande and I. Udeh, (2016). "Optimization of experimental conditions for biodiesel production", Int. J. Eng. Technol., 12: 130-133.

[9] Demirbas, A.M. (2013). Nigeria Oilseeds and Products Annual 2006 USDA: Lagos, pp 1-9.

[10] Dube, C. K. and Mishra, L. P., (2016). "Trans-esterification of vegetable oil for use as diesel fuel: A progress report”. ASAE Paper No. PNWS90-610. ASAE St Joseph. MI 49085.

[11] Enkweremadu, C.C. and M.M. Mbarawa (2019). Technical aspects of production and analysis of biodiesel from used cooking oil-A review. Renewable Sustain. Energy Rev., 13: 2205-2224.

[12] Folami and Inegbedion (2019). "Optimization of Biodiesel Production from Palm Kernel Oil by Transesterification using Response Surface Methodology", Higher National Diploma Project, Department of Chemical Engineering, Lagos State Polytechnic, Lagos, Nigeria

[13] Gerpen, J. H., (2005). "Effect of biodiesel structural configuration on its ignition quality", Int. J. Energy Environ., 1: 295-306.

[14] Gupta, P.K., Kumar, R. Panesar, B.S. and Thapar, V.K. (2017). "Parametric Studies on Bio-diesel prepared from Rice Bran Oil”. Agricultural Engineering International: the CIGR Ejournal. Manuscript EE 06007. Vol. IX.

[15] Khan, H. E., (2012). "Biodiesel fuel production by trans-esterification of oils". Journal of Bioscience and Bioengineering 92 (5), pp. $405-416$. 
[16] Kyu-Wan, P., Singh, R.N., Singh, S.P. and Pathak, B.S. (2017). "Performance of renewable fuel-based CI Engine", Agricultural Engineering International: the CIGR Journal of Scientific Research and Development. Manuscript EE 010014 Vol. IX.

[17] Lewis, M. A. (2007). “Attempts to reduce $\mathrm{NO}_{\mathrm{x}}$ exhaust emission by using reformulated biodiesel”,. Fuel Processing Technology 88:693 - 699.

[18] McNeff, A. and Van Gerpen, J., H., (2013). The effect of biodiesel oxidation on engine performance and emissions. Biomass and Bioenergy 20:317 - 325 .

[19] Meher, D. (2012). "Fuel lubricity". Industrial Lubrication and Tribology. 50(3): 108-118.

[20] Patrick, T. J. and Pimentel, D. S. (2015). "Biodiesel processing and production". Fuel Processing Technology, pp. 1-11.

[21] Ramadhas, E. R., Schwab, A.W., M.O. Bagby and B. Freedman. (2015). "Preparation and properties of diesel fuels from vegetable oils". Fuel 66: 1372-1379.

[22] Sahoo, R. S., Ramirez-Verduzco, L.F.,Rodriguez-Rodriguez, A.D.R.Jaramillo-Jacob, (2007). "Predicting cetane number, kinematic viscosity, density and higher heating value of biodiesel from its fatty acid methyl ester composition", Fuel, 91: 102-111.

[23] Talukder, Y., Niju, S., Begum, K. M. M. S., Anantharaman, N. and Raj, S. M. (2015). "Trans-esterification of jatropha oil using mixture of natural shells as solid catalyst", Biofuels. Available in http://dx.doi.org/10.1080/17597269.2015.1138036

[24] Tapasavi, M.E, Van Gerpen J.H. (2013). "Fuel property effect on biodiesel”. ASAE Paper No. 036034.

[25] Warzyniak, Z. M., Rezaei, R., Mohadesi, M. and Moradi, G. R. (2015) Optimization of biodiesel production using waste mussel shell catalyst. Fuel 109: $534-541$.

[26] Wenzel, T. E. (2016). "Biodiesel processing and production”. Fuel Processing Technology, pp. 1-29

[27] Xuan Wu (2017), "Water cleaning of biodiesel. Effect of catalyst concentration, water amount and washing temperature on biodiesel obtained from rapeseed oil and used oil”. Ind. Eng. Chem. Res., 49: 4436-4443.

[28] Yaakob, D. E., Ajav, E.A. and A.O. Akingbehin. (2013). "A study of some fuel properties of local ethanol blended with diesel fuel". Agricultural Engineering International: the CIGR Journal of Scientific Research and Development. Manuscript EE 01003 Vol. IV.

[29] Yuan, Y, A. Hansen and Q. Zhang. (2014). "The specific gravity of biodiesel fuels and their blends with diesel fuel". Agricultural Engineering International: the CIGR Journal of Scientific Research and Development. Manuscript EE 04004 Vol. VI.

[30] Zhao,Y. A., Tan, K.T., K.T. Lee and A.R. Mohamed, (2009)."Potential of waste palm cooking oil for catalyst-free biodiesel production", Energy, 36: 2085-2088.

[31] Warzyniak, Z. M., Rezaei, R., Mohadesi, M. and Moradi, G. R. (2015) Optimization of biodiesel production using waste mussel shell catalyst. Fuel 109: $534-541$. 